\title{
Trabalho de crianças e adolescentes: os desafios da intersetorialidade e o papel do Sistema Único de Saúde
}

\author{
Adolescent and child labor: the challenges \\ of inter-sector work and the role of the U nified \\ $\mathrm{N}$ ational H ealth System
}

Letícia Coelho da Costa Nobre 1

\footnotetext{
1 Fundacentro,

Fundação Jorge Duprat

Figueiredo de Segurança

e M edicina doTrabalho.

Centro Regional da Bahia.

Rua Alceu Amoroso Lima

142, Pituba, 41820-770,

Salvador BA.

letnobre@fundacentro-ba.

gov.br
}

\begin{abstract}
This paper presents the role of the public health sector and the intersectorial action in the issue of the child labor, considering the experience of the W orker's H ealth Study Center of the State D epartment of $\mathrm{H}$ ealth in the Bahia State Program for the Child Labour Prevention and Eradication, period 1997 to 2001. Some aspects are pointed out, as the child labour invisibility to health services, the fragmentation between surveillance and health care, the different compliance and participation of the institutions in the program, the relevance of the role of communitary and nongovernamental organizations on the management and supervising public policies. It is concluded that is necessary to build the concept of child labour as an object of public health, and to improve intersectorial planning practices by means of creating empowering and sharing spaces and joining interests, learnings and practices from the various organizations.

Key words Child labour, Intersectorial action, W orker's health, Public policies
\end{abstract}

Resumo Este artigo apresenta uma reflexão sobre o papel do setor saúde (do Sistema Ú nico de Saúde) e sobre os desafios da prática de intersetorialidade na prevenção e erradicação do trabalho de crianças e adolescentes, a partir da experiência do Centro deEstudos da Saúde do Trabalhador, junto ao Programa de Prevenção e Erradicação do Trabalho Infantil do Estado da Bahia, de 1997 a 2001. Discute aspectos importantes como a invisibilidade do trabalho infantil para o setor saúde, as práticas fragmentadas de atenção e vigilância em saúde, a inserção e a adesão diferenciada dos setores no Programa, e a importância das organizações e representações da sociedade ci vil no processo de gestão e acompanhamento das políticas públicas. Conclui pela necessidade de construção do trabalho infantil como objeto da saúde coletiva e de qualificação das práticas de planejamento intersetorial que se constituam em um espaço de poder compartilhado e de arti culação de interesses, saberes e práticas das diversas organizações.

Palavras-chave Trabalho Infantil, Intersetorialidade, Saúde do trabalhador, Políticas públicas 


\section{Introdução}

Segundo estimativas da O rganização Internacional do Trabalho, 352 milhões de crianças e adolescentes trabalhavam no mundo no ano 2000. Dessas 246 milhões comprometidas na definição de crianças (idades entre 5 e 14 anos), cerca de 171 milhões encontravam-se em atividades denominadas "piores formas de trabalho infantil" (ILO, 2002). Na América Latina e Caribe eram 17,4 milhões de crianças trabal hando nesse mesmo ano, sendo que $16 \%$ dessas crianças tinham entre 5 e 14 anos. É o terceiro maior percentual dentre as grandes regiões do mundo (ILO ,2002). No Brasil, a Pesquisa Nacional por Amostra de Domicílio (PNAD) realizada pelo IBGE estimou para 1998 a existência de cerca de 7,7 milhões de crianças e adolescentes entre 5 e 17 anos de idade trabalhando (Schwartzman, 2001). As características da inserção das crianças e adolescentes no trabalho variam entre as regi ões, entre os grupos etários, entre sexo e segundo área urbana e rural. A região N ordeste é a que contribui com o maior número de crianças trabalhadoras, apresentando mai or concentração em áreas rurais e atividades agrícolas, com alto percentual de trabaIho não remunerado, como forma de complementação do trabal ho do núcleo familiar. Segundo a PNAD, em 1998 o Estado da Bahia tinha um total de 898.487 crianças e adolescentes trabal hando, sendo dois terços dessas em áreas rurais (Schwartzman, 2001).

A despeito de $o$ trabalho infantil ser um fenômeno antigo no mundo, havia uma tendência de queda especialmente nos países centrais, onde as condições de trabal ho apresentaram melhorias e vigoraram políticas de bem-estar social, até a segunda metade do século passado. Atualmente, apesar de concentrar-se nos países periféricos, observa-se um recrudescimento dele mesmo nos países centrais, sendo apontado pelo movimento sindical brasileiro e outros setores como uma das faces mais perversas do mundo do trabalho contemporâneo (Dieese, 1997).

Pesquisadores, profissionais, instituições e entidades que trabalham com essa questão no Brasil são praticamente unânimes em apontar como principais causas da existência do trabaIho infantil aquelas de ordem estrutural como a concentração de renda, a precarização das re lações de trabal ho, os altos níveis de desemprego, a falta de uma política educacional integral (Dieese, 1997; Schwartzman, 2001). Por outro lado, assumem fundamental importância aspectos e dimensões de ordem simbólica, cultural e ideológica, como o papel que a sociedade atribui ao trabalho, a adesão das famílias (mães e pais) a esses valores, a conseqüente naturalização do trabalho infantil, que freqüentemente passa a ser tolerável e, em algumas situações, até desejável (Dieese, 1997; Gomez \& M eirelles, 1997; Alvim, 1994). N este caso, antes de ser um problema, o trabalho infantil é apontado como solução; solução às carências do sistema educacional, à pobreza, à violência das ruas. Esses aspectos - estruturais e culturais/ simbólicos - e essa dualidade - problema/solução - constituem o cerne deste objeto e explicitam a complexidade da questão para todos aqueles que precisam ou se propõem a enfrentar o desafio de trabal har para a erradicação do trabalho infantil, ao tempo em que demandam o estabelecimento de estratégias múltiplas, de ações intersetoriais e de políticas públicas articuladas.

O objetivo deste artigo é apresentar uma reflexão sobre o papel do setor saúde (do Sistema Ú nico de Saúde) e sobre os desafios da prática de intersetorialidade na prevenção e erradicação do trabalho de crianças e adolescentes, a partir da experiência do Centro de Estudos da Saúde do Trabal hador, junto à Comissão Interinstitucional de Prevenção e Erradicação do Trabalho Infantil do Estado da Bahia, nos anos 1997 a 2001.

\section{A intersetorialidade}

A questão da "promoção da saúde" tem sido discutida em fóruns e conferências internacionais, com enfoques diversos, desde meados do século passado. Em 1978 a intersetorialidade é definida, pela O rganização M undial da Saúde, como uma estratégia para atingir Saúde para Todos no Ano 2000. N as últimas duas décadas 0 debate sobre promoção da saúde enfatiza as propostas de "cidades saudáveis, das políticas públicas saudáveis e da ação intersetorial" (Teixeira \& Paim, 2002). No Brasil, esses temas são absorvidos e difundidos no contexto do processo de reforma sanitária e de implementação de mudanças de políticas de saúde e reorganização da gestão e dos serviços de saúde. A relevância da ação intersetorial encontra eco no bojo da discussão dos modelos assistenciais, especialmente naquelas propostas de vigilância à saúde em territórios definidos. Aqui a estraté 
gia de promoção da saúde e seu alcance intersetorial efetivo são compreendidos como motores de formulação de políticas públicas capazes de gerar qualidade de vida (Paim, 2002).

A necessidade de ações intersetoriais também é apontada pelo conjunto da sociedade representada pelos del egados da 11a Conferência N acional de Saúde que defendem como primeiro ponto da agenda para a efetivação do SUS e do controle social "a melhoria das condições de saúde e da existência efetiva de políticas sociais intersetoriais e de um compromisso irrestrito com a vida e a dignidade humana, capaz de reverter os atuais indicadores de saúde, contribuindo assim para a melhoria da qualidade de vida da população" (Conferência Nacional de Saúde, 2001). No capítulo da Organização da Atenção à Saúde, Atenção Básica: Rede, PSF e PACS é expressada a necessidade de "implementar políticas intersetoriais de promoção da saúde por meio do conceito de municípios saudáveis" (Conferência Nacional de Saúde, 2001).

A intersetorialidade tem sido definida como um "processo em que os objetivos, as estratégias e os recursos de cada setor se consideram segundo suas repercussões e efeitos nos objetivos, estratégias, atividades e recursos dos demais setores" (Análisis, 1992, citado por Teixeira \& Paim, 2002). Em conferência internacional promovida pela OM S em 1997, propõe-se que a "ação intersetorial para a saúde" compreenda "uma relação reconhecida entre uma ou várias partes do setor saúde com uma ou várias partes de outro setor, que se tenha formado para atuar em um tema visando alcançar resultados de saúde (ou resultados intermediários de saúde) de uma maneira mais efetiva, eficiente ou sustentável, do que poderia alcançar o setor saúde agindo por si só (WHO , 1997 citado por Teixeira \& Paim, 2002).

U ma questão central diz respeito à operacionalização dessas propostas de intersetorialidade. Diversos autores chamam a atenção para a importância de se construírem formas mais adequadas de planejar, organizar, conduzir, gerir e avaliar tais intervenções, bem como sobre a "necessidade de coerência entre os propósitos definidos e métodos selecionados (Testa, 1992), de modo a permitir o desencadeamento de um processo de reorganização das práticas gerenciais, dos formatos organizacionais e, sobretudo, dos processos de trabal ho no âmbito das instituições envolvidas" (Teixeira \& Paim, 2002).
O utra vertente dessa discussão aborda as questões do exercício do poder, especialmente no interior dos aparel hos de estado e nos processos de formulação de políticas públicas, chamando a aten ção para os constrangimentos e subordinações a interesses das elites locais, para o corporativismo, para as práticas clientelistas etc., que devem ser contemplados no planejamento estratégico, de forma a se obter uma redistribuição do poder e reorganização dos processos de trabalho (Teixeira \& Paim, 2002).

\section{O Programa de Prevenção e Erradicação do Trabalho Infantil na Bahia - PETI}

O PETI, inicialmente denominado Paipeti Programa de Ações I ntegradas de Prevenção e Erradicação do Trabalho Infantil, foi criado a partir do estabelecimento da Comissão Interinstitucional de Prevenção e Erradicação do Trabalho Infantil (Competi), instituída pelo Governo do Estado da Bahia, em 1996. Essa comissão é coordenada pela Secretaria do TrabaIho e da Ação Social do estado, contando com representações da Secretaria da Saúde do Estado, da Delegacia Regional do Trabal ho, da Fundacentro, da Universidade Federal da Bahia, do Ministério Público, do Unicef, do Conselho de D efesa da Criança e do Adolescente, da Federação dos Trabalhadores na Agricultura do Estado, do M ovimento de Organização Comunitária, dentre outras.

A partir de um processo de planejamento que envolveu as representações estaduais e regionais, foi selecionada para início do programa a Região Sisaleira, que abrange 27 municípios e 757.165 habitantes, correspondente a $6,4 \%$ da população total do Estado (IBGE, 1991). Essa região é responsável por $80 \%$ da produção brasileira de sisal. Trata-se de uma região com pouca diversificação de atividades produtivas; em alguns municípios aparecem também atividades de mineração, como produção de pedras em veios a céu aberto, também com presença de trabalho de crianças e adolescentes. 0 processo de produção do sisal é bastante rudimentar, com baixo índice de aproveitamento do produto. As agruras da seca nordestina acarretam drástica redução das áreas de plantio. É uma região marcada pela pobreza e precariedade das condições de trabal ho, segurança, saúde e saneamento básico, pela predominância de mão-de-obra familiar e de contratos verbais, de baixa remuneração; somente $2 \%$ 
dos trabalhadores possuem carteira assinada e concentração de renda no final da cadeia produtiva (no beneficiamento da fibra e na industrialização - fabricação de fios e cordas de sisal). A região selecionada já apresentava uma importante organização comunitária, com razoável poder de mobilização social, representada pelo M ovimento de Organização Comunitária (MOC) e pela seção regional e local da FETAG. Esse fato, aliado aos indicadores de pobreza e ao contingente de crianças trabal hando nos campos de sisal, foi o principal critério de sel eção da área para início do programa ( Bahia, 1997; 1999; Carvalho \& M aia, 2003).

O PETI iniciou-se em 1997 em cinco municípios; em 1998 foi expandido para 17 municípios e, em 1999, já atingia todos os 27 municípios da região sisaleira. 0 plano de ampliação elaborado para 2000/2001 previu sua expansão para municípios de médio porte, buscando atingir outras atividades produtivas que não somente a produção si sal ei ra e também crianças em atividades urbanas, especial mente em Salvador. Em 2001, o PETI englobava 40 municípios ( $10 \%$ dos 417 municípios baianos) e 66.175 crianças e adolescentes. Em 2002 o Programa estava implantado em 93 municípios, com previsão de envolver cerca de 120.000 crianças (Carvalho \& M aia, 2003).

\section{As linhas de ação e a repartição de atribuições}

Como em outras regiões do país, o PETI na região sisaleira da Bahia desenvolveu-se a partir das diretrizes do Fórum Nacional de Erradicação do Trabalho Infantil, orientando-se para a retirada de crianças do trabalho, mediante 0 repasse de $R \$ 50,00$ por cada criança trabal hando no sisal, na faixa etária de 7 a 14 anos, sendo $\mathrm{R} \$ 25,00$ para a família e $\mathrm{R} \$ 25,00$ para a Secretaria M unicipal de Educação. Às secretarias municipais de Educação, com o apoio da Secretaria Estadual de Educação, cabia manter as crianças na escola durante dois turnos, implantando a jornada ampliada e promovendo atividades de lazer, recreação e culturais; estava previsto também o desenvolvimento de modelo educacional próprio para a região sisaleira ( $\mathrm{Ba}$ hia, 1997).

A Universidade Federal da Bahia realizou o cadastro das crianças e famílias, com levantamento de informações sobre suas condições de vida e trabalho, como forma de obter um diag- nóstico inicial e um banco de dados, a partir do qual as crianças foram inscritas no programa. Esse cadastramento, sob responsabilidade da Universidade, e a realização de concurso, com prova escrita e entrevista, para sel eção dos monitores que acompanhavam as famílias, foram considerados de fundamental importância para garantir a isenção na identificação e escoIha dos beneficiários do programa (Carvalho \& M aia, 2003). Esse processo ocorreu para cada município da região sisaleira incorporado nas fases posteriores de ampliação do Programa.

A promoção e fiscalização dos direitos do cidadão menor de idade couberam aos ConseIhos Tutelares da Criança e do Adolescente, à Delegacia Regional do Trabalho, às Promotorias de Justiça do M inistério Público e às organizações não-governamentais, que deveriam identificar, fiscal izar e encaminhar casos para as devidas providências (Bahia, 1997). Caberessaltar que antes da criação do PETI, a DRT já havia realizado um diagnóstico sobre as áreas mais críticas em termos da existência de crianças trabalhando em atividades penosas e degradantes (Carvalho \& M aia, 2003), cujos resultados foram apresentados nas primeiras oficinas que decidiram o início do programa.

Órgãos do governo estadual, contando com recursos próprios e também recursos federais, implantaram programa e ações visando a geração de emprego e renda, como incentivo às famílias para adoção de outras atividades complementares ao cultivo e beneficiamento do sisal, como a caprinocultura, fabricação de queijos, artesanato. Cursos profissionalizantes foram oferecidos pela Secretaria do Trabal ho e Ação Social do Estado e foram incentivadas e criadas algumas cooperativas de produtores rurais. À Secretaria da Agricultura do estado coube incentivar e assessorar a implantação de projetos de hortas escolares comunitárias e a inserção de outras culturas - feijão, milho, algaroba, goiabeiras, cajueiros, como forma de diversificação do cardápio e combate à desnutrição infantil (Bahia, 1997).

A Secretaria da Saúde do Estado era representada na Comissão do PETI por uma técnica do Cesat e por uma técnica do programa de atenção à saúde da criança (depois da coordenação da atenção básica). As ações identificadas como de sua competência foram: promover a melhoria da atenção à saúde; capacitar os agentes de saúde; cadastrar crianças com problemas de saúde decorrentes do trabalho; estabelecer medidas curativas e implementar ações 
básicas de saúde (Bahia, 1998). Assim, os municípios, com supervisão e assessoria do estado, deveriam promover o incremento das ações de atenção à saúde, voltadas para o grupo de 7 a 14 anos.

A participação do Cesat no PETI durante os primeiros anos consistiu principalmente na organização e participação das oficinas de planejamento, especialmente nos níveis regional e municipal, durante as quais pouca visibilidade era conferida ao seu papel específico. U ma vez que as questões de saúde infantil cabiam muito mais ao nível da atenção básica desenvolvida pelos municípios, e que se tratava de retirar as crianças do trabal ho e não de dar-Ihes boas condições de trabalho, o que caberia, então, à equipe de saúde do trabalhador? Assim, ao Cesat coube a realização de um mapeamento de riscos ocupacionais, com avaliação das condições de trabal ho na produção do sisal. As inspeções feitas em 1999, em 28 fazendas e batedeiras de sisal de nove municípios em que - Programa já estava implantado, identificaram trabalho de crianças nas atividades de corte, apanha, carregamento e pesagem do sisal, que demandam esforço físico e acarretam sobrecarga de estruturas osteomusculares, além de risco de acidentes, tais como perfuração de olho pelo corte e transporte da planta do sisal (Bahia, 1999). Outra vertente foi a participação na proposição de mudança tecnológica - criação de protótipo de máquina desfibradora de sisal com mecanismo de proteção contra amputações de dedos e mãos. No entanto, nessa atuação predominava a observação do trabalho de adultos, persistindo, de certa forma a questão. $\mathrm{Na}$ busca por essa identidade, chegou-se à definição da necessidade de prover capacitação aos municípios para a identificação de agravos relacionados ao trabalho, para a implementação do sistema de vigilância e para a produção de informações que desvelasse 0 trabal ho de crianças como uma questão de saúde coletiva.

Paralelamente à participação no PETI, em 2001 foi iniciada experiência piloto de capacitação em saúde do trabal hador, de profissionais do Programa de Saúde da Família, seguindo metodologia proposta pelo M inistério da Saúde (Brasil, 2001; 2002), na qual foram incluídos conteúdos relativos ao trabalho de crianças e adolescentes e contou com a participação de auditores do trabalho da Delegacia Regional do Trabalho da Bahia. A despeito de ter sido realizada em municípios de outras regiões, foram explicitados aspectos importantes que interferem nas possibilidades de enfrentamento dessa questão pelas equipes do PSF, do SUS, do Cesat e da DRT, potencialmente aplicáveis a quaisquer outras equipes e regiões.

\section{Discussão sobre as práticas e desafios da ação intersetorial}

Um primeiro ponto que deve ser ressaltado em relação às práticas intersetoriais nessa experiência é que, a despeito de haver um objeto e objetivos comuns - o trabalho de crianças e adolescentes e sua prevenção e erradicação - e de ter havido um processo participativo de planejamento e de definição de atribuições, pode-se observar que houve diferenças no envolvimento e adesão das instituições e entidades participantes do programa. Isso se deveu tanto às concepções particulares de cada entidade sobre o objeto de trabal ho e seu potencial de contribuição para o tema, quanto ao entendimento que cada instituição tinha sobre o papel das demais. O u seja, havia tanto a questão do entendimento próprio do papel de cada uma, quanto o entendimento de cada uma sobre 0 papel da "outra", resultando em maior ou menor comprometimento de cada instituição com o plano de trabal ho proposto.

$N$ ão é objetivo do presente artigo apresentar uma avaliação sobre o próprio PETI. No entanto, al guns aspectos levantados em reuniões da Comissão e apresentados em relatório (Carvalho \& Maia, 2003) são importantes de ser ressaltados para a análise dos desafios da ação intersetorial. A pesar dos esforços e de iniciativas com bons resultados, como a criação de al gumas cooperativas, com aumento de oportunidades de trabal ho e geração de renda, o PETI manteve-se bastante circunscrito ao pagamento da bolsa, com inclusão de um número muito pequeno de crianças em relação à demanda, tratando-se de um programa pontual, focalizado, com baixo impacto global, não obtendo de fato a mudança da condição de vida das famílias. Da mesma forma, as iniciativas, tanto de programas federais como estaduais, de geração de emprego e renda também foram avaliadas como insuficientes, pontuais e focalizadas. M esmo considerado importante e recomendando a continuidade do PETI, especialmente porque, diferentemente do Bolsa-Escola, exige a saída da criança do trabalho, há o consenso de que são necessárias políticas públicas amplas, que garantam resultados efeti- 
vos e retirem as famílias da situação de miséria em que estão (Carvalho \& M aia, 2003).

Outro aspecto diz respeito à baixa cobrança da atuação dos outros setores, destacando-se aqui o setor saúde, trabalho e educação. Especificamente no caso da educação, foi identificada a baixa adesão do sistema formal de ensino como um todo, especialmente do nível estadual. Houve um descolamento da jornada ampliada em relação às práticas do sistema regular, normal de ensino. A insuficiência qualitativa da escola para dar conta desse objeto é apontada como um dos pontos críticos para o êxito do programa.

Em relação ao papel e práticas das instituições, colocam-se como pontos importantes o fato de elas terem diferentes atribuições, competências específicas, diferentes missões, concepções e lógicas. 0 estabel ecimento de prioridades, é claro, segue essas lógicas. Assim, observa-se que o momento do planejamento conjunto nem sempre é reafirmado nos planos internos de cada instituição, como ocorreu com a área da saúde, que teve ações programadas e não executadas por falta de repasse de recursos financeiros.

0 relatório da equipe da U niversidade aponta como ponto bastante positivo do PETI na região sisaleira o fato de ter havido uma gestão e coordenação participativas e transparentes, destacando-se a Secretaria do Trabalho e Ação Social, o M ovimento de Organização Comunitária, o sindicato de trabal hadores rurais e 0 U nicef, o que, somando-se aos levantamentose acompanhamento cadastral da U niversidade, garantiu relativa isenção e não interferência de interesses políticos outros (Carvalho \& M aia, 2003). No entanto, a própria ausência das instituições de educação, saúde e trabal ho nesse destaque indica a fragilidade da representação desses setores e uma certa concentração de poder nas instituições coordenadoras.

Por outro lado, as mesmas autoras identificam a interferência de interesses políticos e a baixa adesão de gestores e prefeitos em alguns outros municípios fora da região sisaleira, nos quais o processo de implantação do PETI transcorreu de forma menos participativa. "E onde a mobilização é mais reduzida, a rede de associações mais frágil e as lideranças menos ativas, o Programa enfrenta dificuldades: os grupos gestores não conseguem se consolidar, e nem sempre as elites locais se sensibilizam quanto à questão do trabal ho infantil, deixando de dar a contrapartida do município ou resistindo à participação e ao controle da sociedade, acostumados às velhas práticas patrimonialistas e clientelistas e à "cultura do favor" que vem permeando os programas sociais no Brasil" (Carvalho \& M aia, 2003).Um paralelo pode ser traçado sobre esses elementos da representação de interesses no exercício da intersetorialidade com as experiências relativas ao controle social no SUS. Côrtes (2000), em sua análise sobre as potencialidades de partici pação e controle social no âmbito dos consel hos de saúde, destaca que clientelismo e paternalismo ainda são características marcantes nas relações entre Governo e grupos de interesse no Brasil, especialmente nas pequenas cidades, nas áreas rurais menos industrializadas do País; embora reconhecendo a potencialidade para a consolidação de formas mais democráticas de representação de interesses, afirma que os consel hos têm seu funcionamento limitado e condicionado pela "realidade concreta das instituições e da cultura política dos municípios brasileiros", e que "será a força das instituições políticas e dos movimentos popular e sindical nas cidades que tornará viável a participação autônoma e consistente de representação dos usuários em consel hos municipais, locais ou gestores" (Côrtes, 2000).

$\mathrm{Na}$ experiência aqui relatada, a despeito de se ter construído o objeto "trabalho infantil" mediante um processo relativamente participativo e democrático, a intersetorialidade mostrou-se de fato um espaço de exercício de poderes e de interesses, por vezes, conflitantes. Há que se estar atento para o risco de, em algumas situações, a interlocução entre governo e sociedade civil "parecer ser transparente", quando pode se tratar de cooptação.

U $m$ outro ponto diz respeito à naturalização do trabal ho infantil e suas justificativas ideológicas, tais como o trabalho enobrece, dignifica o ser humano; ou, é melhor trabalhar do que estar na rua, na marginalidade e na criminalidade, exposto às violências urbanas e do mundo moderno (Alvim, 1994; Gomez \& M eirelles, 1997; Dieese, 1997); essas idéias podem ser encontradas no discurso de pessoas e institutos importantes, tais como a escola, as equipes de saúde e as próprias famílias. Essas referências aplicam-se sempre às crianças e adolescentes de classes sociais desfavorecidas e não seriam pensadas em relação às crianças de classes sociais ricas, onde a valorização dos aportes educacionais e culturais ganha uma relevância muito maior que o trabalho em sua formação. Assim, as políticas e projetos educacionais pro- 
fissionalizantes, ao invés de contribuírem para o fomento da cidadania, acabam reforçando uma situação de exclusão social ( Gomez \& M eirelles, 1997; Dieese, 1997; Scanlon et al., 2002).

A par disso, pesquisas do Dieese (1997) e da própria OIT (Schwartzman, 2001) vêm demonstrando que tanto 0 aporte de recursos financeiros ao orçamento familiar, obtido com 0 trabalho de crianças e adolescentes, é bastante pequeno, quanto os conteúdos e as condições de trabalho dessas crianças e adolescentes não trazem nenhuma diferença em relação ao trabalho de adultos. Ao contrário, submetem essas crianças a condições de trabalho desumanas, desgastantes, precárias, sem proteção social, com enormes conseqüências a seu futuro e ao futuro da nação. Dessa forma, os próprios argumentos da necessidade econômica, da possi bilidade de saída da situação de miséria e do caráter educativo do trabalho devem ser recolocados em outro patamar pelos atores sociais. $\mathrm{E}$ as políticas públicas intersetoriais, de acesso e melhoria da qualidade das escolas, incluindo a bolsa escola ( ou bolsa família), de atenção integral à saúde (incluindo a promoção e a vigilância da saúde), de geração de emprego e renda, devem ser reconhecidas por todos como mais importantes e efetivas para a diminuiç̧ão das desigualdades sociais e a erradicação do trabaIho infantil.

\section{Algumas questões sobre o papel do setor saúde}

O papel do setor saúde não aparecia de forma clara e explicitada, nem para ele nem para os demais. A representação na Comissão era do nível estadual, com alguma participação dos níveis locais. No entanto, não aparecia a relevância de sua contribuição. Em primeiro lugar, identifica-se a questão do não reconhecimento do trabalho infantil como problema de saúde pública. Esse é um objeto/problema que não foi identificado originalmente pela saúde. Ele surge externamente ao setor; são os organismos internacionais, é o governo federal, é o Fórum Nacional, éo M inistério do Trabalho e Emprego, é o Unicef, é a comissão estadual, que o colocam em cena. Assim, a saúde, o SU S deve assumi-lo e construir sua própria concepção a respeito dele.

Em geral, as crianças e adolescentes são vistos como "grupos de risco" ou como "grupos vulneráveis" para problemas como desnutrição, doenças infecciosas, gravidez na adolescência, até consumo de drogas e violências. Questões importantíssimas e que, inclusive, podem ter determinações comuns. N o entanto, não estar na escola (numa boa escola) e ter que estar trabal hando (algumas vezes em condições absolutamente perversas, inclusive sujeitas àquelas mesmas violências que se supõe seriam evitadas pelo trabalho, como é comum no trabalho doméstico ou no tráfico de drogas) não é entendido como uma forma de violência. 0 trabalho infantil é invisível para os serviços e práticas de saúde. Quando aparece, nossa concepção tende a aproximar-se freqüentemente da concepção veiculada de que o trabalho infantil é solução para o problema da miséria social.

Do ponto de vista das estratégias de intervenção possíveis no âmbito do SUS, o que se coloca é bastante complexo. U $\mathrm{m}$ dos aspectos diz respeito aos princípios que têm estruturado as práticas de vigilância sanitária e também, de forma similar, aquelas historicamente desenvolvidas pelo M inistério do Trabal ho eEmprego. Essas ações são freqüentemente mediadas pelo conceito de fiscalização, entendido como uma ação de caráter pontual e que se dirige para verificação do cumprimento de determinadas normas e leis estabelecidas, tendo por finalidade impor sanções e dificilmente comportando a contribuição de outras áreas disciplinares (M achado, 1996). N os últimos anos, várias iniciativas têm imprimido novas características ao trabalho de inspeção, tentando viabilizar uma prática mais processual e orientada pela epidemiologia e pelas ciências sociais, bem como inserindo a noção de processo pedagógico em suas práticas (Fernandes \& N obre, 2002). Tanto o caráter pedagógico quanto a concorrência de práticas interdisciplinares são fundamentais para se construírem experiências exitosas de vigilância e prevenção do trabalho infantil.

No tocante à atenção básica, exemplar éa fala de vários técnicos do Programa de Saúde da Família (PSF), que discutem o que fazer a partir da identificação de uma situação de trabalho infantil em uma família sob seus cuidados. Estão em jogo preocupações de ordem ética e de respeito às opções das famílias. A relação da equipe do PSF com a família e a comunidade pressupõe um pacto de confiança, que poderia ser quebrado com o encaminhamento de denúncia ou notificação de uma tal situação às autoridades e órgãos competentes, tais como vigilância sanitária, del egacias regionais do tra- 
balho, consel hos tutelares etc. Por outro lado, a identificação dessa situação poderia ensejar o estabel ecimento de orientações, de contatos com as escolas, de acesso ao programa de erradicação e recebimento de bolsa, na ótica, por exemplo, de um evento sentinela, a partir do qual providências deveriam ser tomadas. Em qualquer desses casos, a família não é somente um grupamento de pessoas que vivem juntas, objetos dessas políticas. Como apontam Bastos \& Trad (1998), em um outro contexto, mas que também pode ser traduzido aqui, as famílias ocupam espaços diferenciados em sua luta pela sobrevivência e pela reprodução da vida. E, ao ocupar estes espaços, estabelecem relações de convivência, conflituosas ou não, trocam experiências, acumulam saberes, habilidades, hábitos e costumes, produzindo e reproduzindo concepções e culturas. Assim, as reflexões sobre a situação encontrada e a busca de soluções devem ser compartilhadas com a família, na busca de um agir participativo e de trocas de intersubjetividades.

De forma resumida, os principais nós críticos no âmbito do SUS que podem ser destacados para o enfrentamento do trabalho infantil são: 1) a invisibilidade do trabal ho da criança e adolescente para o SUS; 2) a invisibilidade do impacto do trabalho na saúde; 3) a desarticulação entre assistência e vigilância; 4) a concepção compartimentalizada de vigilância; 5) a prática maior do SUS e dos centros de referência com o trabalho formal do que com o trabaIho informal, doméstico e ou precarizado; 6 ) as limitações relativas às capacidades e qualificações da equipe técnica; aqui se coloca a necessidade de equipes multiprofissionais e práticas interdisciplinares; 7) a insuficiente produção de informações e conhecimento, tanto sobre 0 trabal ho de crianças quanto sobre seus efeitos; 8) a ainda incipiente produção de experiências e reflexões sobre práticas intersetoriais; 9) o financiamento das ações na ótica da intersetorialidade e da promoção da saúde, ou seja, a garantia do aporte de recursos para aqueles projetos planejados e pactuados inter setorialmente.

\section{Conclusão}

Se analisadas em toda sua extensão e profundidade, as conseqüências sociais, psíquicas e físicas do trabalho infantil, tanto para a criança, quanto para a família e para a nação, justificam plenamente ser colocado de pronto como objeto da saúde coletiva (Gomez \& Thedim-Costa, 2003; Gomez \& M eirelles, 1997).

É imperiosa a necessidade de construção desse objeto: a criança e 0 adolescente são outros quando trabalham e as implicações e impactos do trabalho também são outros se realizado por crianças e adolescentes; assim, são necessários outros ol hares e outras investigações, que confiram visibilidade às crianças e seu trabalho.

A discussão atual sobre os modelos de atenção à saúde, especialmente da vigilância à saúde, das estratégias da reorganização da atenção básica e da promoção na ótica de municípios saudáveis (Teixeira et al., 2002), traz um rico instrumental para a elucidação do papel do setor saúde no enfrentamento do trabalho infantil.

0 desafio da intersetorialidade consiste em identificar objetivos comuns e persegui-los mediante um núcleo estratégico de planejamento e definição de prioridades para as ações conjuntas (Fernandes \& Nobre, 2002), de modo a inserir de fato a saúde nas macropolíticas ou nas políticas setoriais, dado que freqüentemente o setor é colocado à margem das definições de diretrizes e prioridades nos planos de desenvolvimento (Nobre, 2001).

Acima de tudo é necessário qualificar nossas práticas de ação intersetorial, desenvolver ...um processo de planejamento e programação que se constitua em um espaço de poder compartilhado e de articulação de interesses, saberes e práticas das diversas organizações envolvidas (Teixeira \& Paim, 2002), que permita a produção de conhecimentos e práticas compatíveis com a resolução dos problemas. 


\section{Referências bibliográficas}

Alvim R 1994. 0 trabalho infanto-juvenil em discussão. Tercei rização: diversidade e negociação no mundo do trabalho. Hucitec, São Paulo.

Bahia 1997. O ficina de Planejamento para Erradicação do Trabalho Infantil na Região Sisaleira do Estado da Bahia. Relatório. Secretaria do Trabalho e Ação Social do Estado da Bahia. Comissão de Prevenção e Erradicação do Trabalho Infantil. (M imeo).

Bahia 1998. Programa de Ações Integradas de Prevenção e Erradicação do Trabalho Infantil - Ações da Saúde. Secretaria da Saúde do Estado da Bahia. Departamento de Vigilância da Saúde. Centro de Estudos da Saúde do Trabalhador (CESAT). (M imeo).

Bahia 1999. M apeamento dos riscos ocupacionais identificados na colheita e beneficiamento do sisal nas regi ões econômicas: N ordeste, Piemonte da Diamantina e Paraguaçu no Estado da Bahia. Documento Técnico N o 018/1999. Secretaria da Saúde do Estado da Bahia. Superintendência de Vigilância e Proteção da Saúde. CESAT.

Bahia 2002. O ficina de avaliação do curso de capacitação da rede básica de saúde do SUS em saúde do trabaIhador. Relatório. Secretaria da Saúde do Estado da Bahia. Superintendência de Vigilância e Proteção da Saúde. CESAT. (M imeo).

Bastos ACS \& Trad LAB 1998. A família enquanto contexto de desenvolvimento humano: implicações para a investigação em saúde. Ciência \& Saúde Coletiva 3(1):106-115.

Brasil 2001. Área técnica de saúde do trabalhador. M ódulo instrucional para capacitação da rede básica de saúde do SU S em saúde do trabalhador. M inistério da Saúde. Secretaria de Políticas de Saúde. Departamento de Ações Programáticas Estratégicas, Brasília. (Mimeo),

Carvalho IM M \& M aia SM R (orgs.) 2003. Programa de erradicação do trabalho infantil - PETI - Trajetória e ben eficiários no Estado da Bahia. Edição UFBA/SETRAS, Salvador.

Conferência Nacional de Saúde 1998. Relatório final da 10a Conferência N acional de Saúde, Brasília-DF, 2 a 6 de setembro de 1996. M inistério da Saúde, Brasília.

Conferência Nacional de Saúde 2001. Relatório final da 11a Conferência N acional de Saúde - Efetivando o SUS: Acesso, Qualidade e H umanização na Atenção à Saúde, com Controle Social, Brasília-DF, 15 a 19 de dezembro de 2000. Ministério da Saúde, Brasília.

Côrtes SM V 2000. Balanço de experiências de controle social, para além dos consel hos e conferências no Sistema Ú nico de Saúde Brasileiro: construindo a possibilidade de participação dos usuários. Caderno da 11ạ Conferência Nacional de Saúde. M inistério da Saúde, Brasília.
Dieese 1997. Trabalho infantil. Dieese, São Paulo.

EH O 1997. Intersectorial Action for $\mathrm{H}$ ealth. A cornerstone for health-for-all in the Twenty-First Century. Report of the International Conference. 23-29 abril. Halitas, Nova Acotia, Canadá

Fernandes RCP \& Nobre LCC 2002. Vigilância de ambientes e processos de trabalho. In L N obre et al. (coords. e revisores). $M$ anual de normas e procedimentos técnicos para a vigilância da saúde do trabalhador. (3a edição revisada e ampliada). CESAT/SESAB, Salvador.

Gomez CM \& M eirelles ZV 1997. Crianças e adolescentes trabalhadores: um compromisso para a saúde coletiva. Cadernos de Saúde Pública 13(Supl. 2):135-140.

Gomez CM \& Thedim-Costa SM F 1999. Precarização do trabal ho e desproteção social: desafios para a saúde coletiva. Ciência \& Saúde Coletiva 4(2):411-421.

IBGE 1991. Censo demográfico.

ILO 2002. Every child counts: N ew Global Estimates on Child Labour. International Labour Organization, Geneva.

M achado JM H 1996. Alternativas e processos de vigilância em saúde do trabalhador: a heterogeneidade da intervenção. Tese de doutorado. Escola N acional de Saúde Pública, Fiocruz, Rio de Janeiro.

N obre LCC 2002. A prática atual de saúde do trabalhador - nós críticos. Anais do Encontro Nacional de Saúde do Trabalhador. 16 a 18 de junho de 1999. MS, Brasília.

Paim JS 2002. Modelos assistenciais: reformulando 0 pensamento e incorporando a proteção e a promoção da saúde, pp. 367-381. In JS Paim. Saúde - política e reforma sanitária. Ed. Cooptec/ISC. Salvador.

Schwartzman S 2001. Trabalho infantil no Brasil. OIT, Brasília.

Scanlon TJ, Prior V, Lamarão M LN, Lynch M A \& ScanIon F 2002. Child labour. Vast problem whose effects on children's health remain largely unstudied. British M edical Journal 325:401-403.

Teixeira CF \& Paim JS 2002. Planejamento e programação de ações intersetoriais para a promoção da saúde e da qualidade de vida, pp. 59-78. In CF Teixeira, JS Paim \& AL Vilasbôas (orgs.). 2002. Promoção e vigilância da saúde. Ed. Cooptec/ISC, Salvador.

Testa M 1992. Pensar em saúde. Ed. Artes M édicas, Porto Alegre.

Artigo apresentado em 16/8/2003

Aprovado em 8/11/2003

Versão final apresentada em 20/11/2003 